\title{
Article
}

\section{Electronic Dunes and Downtown Vibes. The Social Construction of an Underground Electro Scene in Tunisia}

Barone, Stefano

Available at http://clok.uclan.ac.uk/25284/

Barone, Stefano ORCID: 0000-0003-0437-9452 (2019) Electronic Dunes and Downtown Vibes. The Social Construction of an Underground Electro Scene in Tunisia. Popular Music and Society . ISSN 0300-7766

It is advisable to refer to the publisher's version if you intend to cite from the work. http://dx.doi.org/10.1080/03007766.2019.1565627

For more information about UCLan's research in this area go to http://www.uclan.ac.uk/researchgroups/ and search for < name of research Group>.

For information about Research generally at UCLan please go to http://www.uclan.ac.uk/research/

All outputs in CLoK are protected by Intellectual Property Rights law, including Copyright law. Copyright, IPR and Moral Rights for the works on this site are retained by the individual authors and/or other copyright owners. Terms and conditions for use of this material are defined in the policies page. 


\section{Popular Music and Society}

\section{Electronic Dunes and Downtown Vibes. The Social Construction of an Underground Electro Scene in Tunisia. \\ --Manuscript Draft--}

\begin{tabular}{|l|l|}
\hline Full Title: & $\begin{array}{l}\text { Electronic Dunes and Downtown Vibes. The Social Construction of an Underground } \\
\text { Electro Scene in Tunisia. }\end{array}$ \\
\hline Manuscript Number: & RPMS-2017-0032R1 \\
\hline Article Type: & Original Article \\
\hline Keywords: & Tunisia; Electronic Music; Music Scenes; Clubbing; Underground. \\
\hline Abstract: & $\begin{array}{l}\text { The paper explores the electronic music scene in Tunisia after the country's } 2010-2011 \\
\text { revolution. Such a scene developed in the context of a pre-existing "mainstream" club } \\
\text { circuit, which embodied many political and social features of pre-revolutionary Tunisia. } \\
\text { The electro scene activists managed to react against such a mainstream, but they } \\
\text { were obliged to borrow its infrastructures and thus negotiate with its social } \\
\text { characteristics. Different sections of the scene accepted or refused different elements } \\
\text { of the perceived mainstream. As a result, they produced different and conflicting } \\
\text { understandings of the local "underground." }\end{array}$ \\
\hline
\end{tabular}




\section{Electronic Dunes and Downtown Vibes. The Social Construction of an Underground Electro Scene in Tunisia}

\section{Stefano Barone}

Griffith Centre for Social and Cultural Research; Griffith University; Brisbane (QLD) Australia

Contact: stefanobarone@gmail.com

Notes on contributor: Stefano Barone holds a $\mathrm{PhD}$ in Sociology from Griffith University (QLD, Australia). His thesis is called "Fragile Scenes: Metal, Rap, and Electro in Post-Revolutionary Tunisia", and is centred on the study of music scenes in a Muslim country undergoing a complex political phase that followed the so-called Arab Springs. Stefano's interests involve the globalisation and localisation of popular culture in Global South contexts, the debate on youth subcultures and post-subcultures, and the vicissitudes of pop culture in the Arab/Muslim world. 


\section{Electronic Dunes and Downtown Vibes. The Social Construction of an Underground Electro Scene in Tunisia}

The paper explores the making of an electronic music scene in Tunisia, before and after the country's 2010-2011 revolution. Such a scene developed in the context of a pre-existing "mainstream" club circuit, which embodied many political and social features of pre-revolutionary Tunisia. The electro scene activists managed to react against such a mainstream, but they were obliged to borrow its infrastructures and thus negotiate with its social characteristics. Different sections of the scene accepted or refused different elements of the perceived mainstream. As a result, they produced different and conflicting understandings of the local "underground."

\section{Word count: 10.879}

Keywords: Tunisia, electronic music, music scenes, clubbing, underground.

\section{Introduction}

I moved to Tunisia after completing high school. It was 2006: I was eighteen, maybe nineteen years old. I did it on a whim. ... I remember I was like "I'm young; I make alternative music; I'm quite politically committed; I'm against the Ben Ali regime. ... Well there must be people akin in Tunisia! And I've got to meet them." ... My arrival in Tunis was... funny. ... I had a cousin who wasn't at all into the underground, and he brought me to all those super-trendy, expensive venues where they played progressive house.... One night, I was in such a club in Sousse ... and I asked the DJ if I could mix. It was incredible: a lot of people came to the DJ booth to see me mix. After the set, I met someone 
who started booking me for DJ sets all around the country. It was the Ben Ali era: you had all those DJs coming by, and [the organizers] put "Foreign top DJ" on the flyers in order to give the sets a value. ... I'm sorry, that was so stupid! I didn't like to be presented as a French DJ. ... I went on for a bit, and then I stopped. ... I felt like [I was] selling out, betraying my ideas, my friends. It was a matter of universe. It was a problem of mixing in places in which, if you're not rich, you can’t get in. In which if you do not conform you can't get in. ... And I wasn't a conformist. At the same time I had started doing interesting things with Skander and Zied. We had started mixing at Le Boeuf sur le Toit with a collective named Electroparty. (Emna)

These words are from Emna ${ }^{1}$, a Franco-Tunisian DJ raised in Paris. In 2006, after completing high school, Emna moved to Tunisia - her country of origin - pushed by a will to discover the local underground. She thus witnessed the dawn of the underground electronic music scene in Tunisia and participated in its development. Not long after her arrival in Tunisia, Emna started DJing in the "mainstream" circuit of seaside clubs, where she was booked as a foreign female DJ. But soon Emna met the people for whom she was looking: musical activists like Skander Besbes and Zied Meddeb Hamrouni, who was operating since 2003-2004 and strove to diffuse genres like drum'n'bass and dubstep among Tunisian audiences.

Emna lived her double life of mainstream DJ and underground pioneer as an existential dilemma, a dilemma which embodied some central dynamics of the Tunisian electro scene. Her narrative photographs were divided between a high-end, "commercial" club scene and a multifaceted underground scene. In different ways, the actors of that underground scene managed to subvert the social exclusiveness and musical homogeneity they perceived in mainstream club life. Their attempts often 
mirrored the sense of cultural crisis and permanent negotiation that Emna evokes in her personal story. This anxiety to challenge the mainstream informed the production of local underground electronic music and club life from the mid-2000s to the present; moreover, it informed the definition of "the underground" itself, as it was conceptualized by the different actors animating Tunisian electro. While most of them felt the urge to work for the underground, they did not agree on what the underground actually was. Each sector of the scene constructed its own underground by negotiating with specific elements of the mainstream - by accepting some of its aspects, and refusing some others. Hence, the electro scene took the shape of a dialectic between different projects of the underground, which interacted through communication and controversies. This article presents such a game of interactions and definitions. It aims to analyze the multiple negotiations that the electro scene undertook with a variously intended "mainstream" - be it musical, social, or political.

Scene is here understood as a space of cultural practices connecting musicians, infrastructures - such as record labels, venues, fanzines, political institutions, and the like - and listeners, in a reciprocally influential fashion. Its theorization stems from the debate on subcultures and post-subcultures. Post-subcultural theorists employed scene as an alternative to the category of subculture, which they perceived as an overly interpretative and deterministic conception of youth cultural identity. In contrast with subculture, scene has been praised as a more flexible, more practice-focused, and more emically sound framework (see Bennett and Kahn-Harris; Bennett and Peterson). I will, in particular, make reference to two theoretical elaborations on the theme of scene: one is Keith Kahn-Harris's idea of scene dynamics as an interaction of construction and structure (100); the other draws inspiration on Bourdieu's concept of fields of cultural production (see Rules). 
For Kahn-Harris, the construction of a scene is its aesthetic and discursive dimension, as it is fashioned by forces both internal and external to the scene itself. Structure is, instead, the ensemble of institutions that compose a scene (i.e., its bands, labels, venues, and the like), and the dimensions that shape its existence and reproduction. The interplay of construction and structure thus gives an identity and a specific existence path to a scene. ${ }^{2}$

Field is a concept designed by Pierre Bourdieu in order to understand particular social universes and their relation to society as a whole. A field is a social universe which has its own features and laws of functioning, that refract and "reconstruct" the social forces acting in society - such as the dynamics of power and the forms of symbolic and material capital that qualify social actors. The field of cultural production - Bourdieu refers to the field of art and culture - exists and evolves, like other fields, both by effect of its own logics and by effect of external social processes. The different actors in the field (such as musicians, genres, cliques, and the like) constitute a game of reciprocally influencing and conflicting positions, which structures the field itself. At the same time, actors' dispositions are constituted by the interplay of their social condition and their place in the field. Dispositions orient their conduct within the field and their understanding of it.

The controversies that animated Tunisian electro were set in the social, cultural, and political ambit of a mutating country. Tunisia is a North African state characterized by a complicated relationship to the world of nightlife sensuality. A former French colony and a Muslim nation, it underwent a policy of "forced modernization" under the regimes of Habib Bourguiba (1956-1987) and Zine el Abidine Ben Ali (1987-2011). To different degrees, both regimes managed to engineer Tunisia as a secular country integrated in the global market economy - as a bridge between the Middle East and the 
West. This politics produced a divide between a depressed, spoliated inland and a rich coastal area where national resources converged, and where tourism and nightlife could flourish. On the coast (also known as the Sahel area), "secular," hedonistic lifestyles were made possible in spite of the poverty and the public morality obligations experienced elsewhere in the country.

This permissive atmosphere acted as a social bubble in which some regime logics were attenuated. At the same time, it was constructed by those very regime logics. It testified of Ben Ali's crackdown against political Islam and its worldview, of a sense of security constructed upon police coercion, and of a permanent liaison between the ruling party and a corrupted tourism sector monopolized by politically backed businessmen. ${ }^{3}$ In 2010, a revolt against Ben Ali started, causing the regime collapse and initiating a democratic age that was constantly under the risk of authoritarian temptations and terrorist menaces (Chouika and Gobe). The post-revolutionary phase witnessed the expansion and success of the electro scene; at the same time, it confronted the scene with new challenges and contradictions.

This paper is based on fieldwork research conducted amidst such a postrevolutionary phase, for eleven months between 2014 and 2015, on the Tunisian electro, rap, and heavy metal scenes. Data come from interviews with 25 members of the electro scene: DJs, producers, journalists, managers of web radios, club owners, festival organizers, and promoters. Further data come from participant observation at club nights and festivals, and from the analysis of media sources such as journalistic articles and social network pages.

In the following pages, I will present the Tunisian electro scene through the interplay of its structure and construction. I will show how that very interplay forced the militants of the underground to negotiate with the infrastructures, logics, and politics of 
what they perceived as the Tunisian nightlife mainstream. This negotiation was undertaken in different ways by different collectives, genre niches, factions in the scene. Such a game of positions structured the field of electro and the substance of its interactions with Tunisian society. I will begin the first section by giving a general definition of the Tunisian electro scene; I will then cast its development in the social and political context of pre- and post-revolutionary Tunisia. Such a context highlights the significance of the scene as a hub for the expression of a socially exclusive form of hedonism; at the same time, it produced conflict between underground activists and the mainstream. In the second section, I will examine the organization of the postrevolutionary "underground" scene and analyze the dynamics that structured its field. Such an analysis will shed a light on scene dynamics and their social underpinnings, illustrating the persistence of exclusion as a feature of the scene and a character on contemporary Tunisia.

\section{Underground versus the Mainstream}

Tunisian producers, DJs, venue owners, music journalists, and clubbers systematically used the term "electro scene" (in French, la scène electro) to talk about the local circuit of electronic music. The scene extended from the party-oriented house music played by DJs such as Da Che to the radical avant-garde sounds of musicians like the producer Ynfl-X. Each scenester had her own idea of the borders of the scene - and, in particular, of what could be considered "truly" underground. Those borders were drawn with reference to musical and aesthetic differences, or on the basis of specific ethical guidelines that discerned a true underground conduct from a mainstream, or a "fake underground" one. Still, the different components of the scene interacted, knew each 
other, played in the same venues, built their discourses with the other electro DJs and producers in mind.

The most commonly identified ancestors of the scene were individuals praised for their pioneering vision, who often became famous abroad and came to be recognized as local electro forefathers only later. An example was techno DJ/producer Mourad Sliti. Under the moniker Tunis Diaspora 216, he and his brothers made a name on dance floors in Europe and the United States beginning in the 1990s. Scenesters also recognized the importance of the E-Fest in the history of local electro. Such a festival, organized by a Franco-Tunisian association, promoted since 2007 a sophisticated take on international electronic music and digital culture. Dance floor sets, experimental music, digital art ateliers have been some of the constitutive experiences of the festival, which along the years has also acted as a vivarium of Tunisian artists.

The above-cited Skander and Zied, respectively known as SKNDR and Shinigami San, were among those who pioneered the first consciously "underground" DJ sets in Tunisia. They animated a string of collectives such as E!, Hextradecimal, Electroparty, and later World Full of Bass. Their first musical steps were at concerts and music festivals organized by universities; later, they obtained a residency at Le Boeuf sur le Toit, a restaurant in the affluent northern banlieue of Tunis. Those residencies were a formative experience for many of the actors of Tunisian electro, and diffused bass music genres (in particular jungle, drum'n'bass, dubstep) among local audiences. ${ }^{4}$ They crossed paths with the Steppers (STPPRS) collective, which organized the first illegal rave parties in the Tunisian countryside. Its animators recalled the Steppers' experience as a "technical school" where many of the protagonists of the later electro scene cut their teeth. Moreover, they were an initial attempt at creating "free spaces" in the strongly securitarian Ben Ali's Tunisia. 
These experiences had to confront the already established club circuit operating in the Sahel. At the beginning of the millennium, nightclubs in the tourist areas of the coast started inviting superstar DJs to Tunisia. Venues like the Calypso and the Pacha (both in Hammamet) began to gradually integrate house and techno in their usual playlists based on commercial disco music and "oriental pop." Club life complemented the appeal of cities such as Hammamet and Sousse, which considered themselves lowrange summertime tourism hubs. Also, clubs in Hammamet, Sousse, or the tourist areas of Tunis's northern banlieue met the expectations of the local middle classes aspiring to the sensual pleasures of nightlife.

Members of the electro scene did not agree on the role of such a club scene in the history of their scene. As noticed in the words of Emna, some of the electro militants developed their efforts as a reaction against the mainstream; others considered the liveliness of the Sahel's disco scene as the cradle where contemporary electro was born, as a sign that Tunisia was a fertile ground for the development of dance culture. A 2010 article on the magazine Jeune Afrique illustrates this point:

Tunisia has become the fifth world destination for clubbing. Hammamet, Sousse, Djerba, and Tunis become, in one night's time, gigantic open air discotheques, animated by the cream of international DJs, such as Warren Nick, David Guetta, Deep Dish, John Digweed or Benny Benassi.

In 2008, the night animated by renowned DJ Tiësto, to which the Citrus Golf club, in Hammamet, lent its green, beat all the records with 10,000 entries, of which almost 3000 VIP and only $10 \%$ being tourists. The event agency which organised the soirée had mobilized 970 police agents, 70 from civil protection, 300 security vigilantes and 150 technicians. The table for 10 people, with two bottles of alcohol, was billed for some 3000 euros. (Dahmani). 
While evidence of Tunisia having been the "fifth world destination for clubbing" cannot be retrieved outside of local media, some members of the electro scene were still persuaded by this narrative at the time of my research. The Jeune Afrique reportage can be read like a cultural statement on the sensual modernism of the late Ben Ali era, and the participation of Tunisian night-clubbers into a global ambiance that broke with the poverty, backwardness, and instability experienced in the rest of the MENA region. In some way, pieces of the current electro scene embraced such a narrative. Not only, as we will see, did the mainstream act as a source for the electro scene's structure, but it also provided elements of the scene's construction through the pioneering modernity of the coastal club landscape, that many other countries in North Africa and the Middle East could not afford due to their cultural and political climate.

\section{Hedonism and Exclusion in the Club Circuit}

The Jeune Afrique article photographs some obsessions of the Tunisian spectacle industry: the emphasis on security, the will to downplay tourism in local nightlife, and the luxury expressed by the prices of alcohol and "tables." These elements survived the Ben Ali era, and became important features of the (still more nuanced) nightlife panorama of the 2010s. The theme of tables and bottles of vodka was a common refrain in the words of electro scenesters. Many of them complained on how most of the local clubbers did not go to the disco for the love of music, but in order to show off: they paid for reserving V.I.P. tables, bought ultra-expensive bottles of vodka, and used the space of the club to parade their social prestige rather than to dance. In many cases, the luxury that clubbers purchased and exhibited in the venues did not correspond to their actual wealth and social position, but was rather the result of loans or impromptu, burdensome economic efforts. This form of social life in the clubs shaped their spatial organization. 
At the time of my research, most electro nights were still staged in places that only had a narrow space for dancing, often studded with tables. The V.I.P. area was, conversely, often of disproportionate dimensions. The manager of the Basement, a club open between 2014 and 2015 and whose aesthetics reminded me of Berlin techno hubs, told me that upon opening all of his friends strongly discouraged him from his idea of a club with no restaurant, no tables, and only a small V.I.P. area, labeling it as a visionary and ruinous project (Amin).

This situation is not uncommon in non-western club settings. Researching the world of Chinese mainstream discos in the 1990s, James Farrer coined the notion of superculture. To Farrer, Chinese clubbers did not seek to belong to a subculture intended as an alternative, selective, authentic collective identity. Rather, they sought to access - at least in the space of discos - a globally indistinct and glamorous consumer modernity. Caitlin Robinson makes a similar point analyzing a mainstream disco club in Lebanon. She takes inspiration from the Arab concept of wasta, which indicates one's volume of personal connections and social influence. To Robinson, "wasta capital" is at the center of the Lebanese disco. Its patrons do not go clubbing for the sake of relaxing and letting go, but rather for exhibiting and cultivating their social status.

Such non-western case studies can be seen as exceptions to the ways in which club cultures have usually been studied, both by scholars who employ a conception of subculture and by those who considered club cultures as an example of the historical crisis, or overall ineffectiveness, of the category of subculture. For example, authors like Steve Redhead - one of the pioneers of post-subcultural critiques - have seen clubs as places in which dancers temporarily lose their structural ties and enjoy a collective experience on the dance floor. Authors such as Andy Bennett and Ben Malbon have employed Michel Maffesoli's category of neotribes as an indicator of the fluid 
collective identities and the Dionysian ambiance experienced by dancers. Malbon, in particular, describes the experience of clubbing as one of losing oneself into an "oceanic experience" (see throughout Clubbing). A similar point is made by Antonio Melechi and Hillegonda Rietveld, who both conceptualize rave and club cultures as ways to experiment a disappearance of the self. Some authors have recurred to Victor Turner's notion of communitas in order to signify the atmosphere sought by club and rave goers: one of collective enjoyment, an emotion-based community in which the individual gets lost (see, for example, St. John). While hedonism, a way of letting go, was at the core of Tunisian clubbing as well, this was in no way coincident with any disappearance of the self. Patterns and needs for social networking, and the exposition of social and economic capital were fundamental aspects of one's presence into Tunisian clubs. We will see below how liberation and luxury coexisted in Tunisian mainstream clubbing, and how this coexistence presented a dilemma to the activists of the local electro underground.

Most Tunisian mainstream clubs were hosted by the local tourist areas: these areas enjoyed special regulations which facilitated the opening of a discotheque, and eased some of the conduct norms that had to be respected elsewhere in the country - for example, in tourist areas one could drink alcohol until late, or could find food more easily during the Ramadan month. While in Tunisia it was prohibited to drink alcohol on the street, some places in the Sahel allowed their customers to drink a beer in their external terraces. Besides legal regulations, social norms about personal conduct were less strict. In the coastal tourist areas women used to wear miniskirts, bikinis, and attire that would be met with sexist reactions, or at least abnormal attention, everywhere else in Tunisia (including downtown Tunis). In the space of clubs and festivals, boys and girls could kiss or have sexually explicit contact; even homosexuals could display hints 
of sensual interaction, defying the national laws which forbid and punish homosexuality.

The bodily freedoms experienced in the club scene testified of its "tourist genealogy." Clubs were born in the areas where French colonizers used to have fun and where, later, western tourists and expatriates would enjoy the most "westernized" and permissive side of Tunisia. Locals would frequent tourist areas for interacting with foreigners (for work and/or pleasure reasons), and to get a chunk of the same permissiveness. As a result, over the course of decades the areas of tourism became the areas of hedonism tout-court. Electronic music flourished in that social context, and contributed to it. The jouissance of electro fostered the liberation of Tunisian bodies in the socially selective tourist areas. As we will see, DJs from the local scene often detested the fact that their audiences were driven to the dance floors because of their need for hedonism rather than their love and knowledge of music. Still, they were hired by clubs and lounges on the coast. Taking part in the nightlife industry was one of the few possibilities they had to make money from their musical activity.

The apparent paradox of dance clubs with narrow dance floors, and whose customers often did not dance, was explained by some of the electro scene members in structural terms. Tunisia was a country marked by a complicated bureaucracy and expensive licenses (for example, the ones for selling alcohol), whose complications were often employed by administrators and police in order to collect bribes or repress unwanted entrepreneurs. Clubs often opened without having all the licenses. Their owners hoped not to be visited by the police and resorted to corruption in order not to be shut down. Still, occurrences such as clubs' closing right before a much-sponsored event or entire electronic music festivals being canceled at the last minute were nor rare. In this situation, entrepreneurs optimized the costs by assembling drinking spaces, 
dancing spaces, and eating spaces. The small supply of venues in the country allowed them to think that dance lovers would join anyway, even if the space was inadequate. Saber, a local music journalist, thus described the situation to me:

Support by the Ministries is quite rare. The Ministry is, if I may say, very slow... Bringing a foreign DJ is not easy. Paying their cachets is not easy; making a festival ... you have to pay $35 \%$ to the State. You have to pay the authorization for the DJ to play, and it's a lot of money! Then it's normal that some festivals end up not taking place. It's not easy to get sponsors. You must have a license from the Ministry of the Interior for being authorized to bring a foreign DJ, and you have to pay customs, because you're importing a product. It's not facilitated at all. When you go to the Calypso to see David Jones, whom in Europe you would pay 20 euros, and in Tunisia you have to pay fifty dinars for a drink, or a pass costs thirty or forty dinars, it's not the same thing. The Ministry doesn't ask for the same fees. How do you pay a DJ who costs 2000 euros, when he comes to Tunisia? Even 1000 drinks at 200 dinars each would not be enough. You have to understand the club owner. (Saber)

The high costs of clubs were matched by strict door selection, making the coastal venues machines of heavy social distinction. It can be argued that most young Tunisians were, in one way or another, prevented from clubbing. Entry and beverage costs, plus the cost of affording a taxi to and from the tourist areas, were a primary instrument of selection. Then, punters whose looks were not reputed to be "well-off" enough by the clubs' bouncers would be excluded from entering. This happened in particular to single males who appeared to come from disadvantaged neighborhoods of the cities or from 
rural areas. As for women, the main discrimination already occurred in the space of the family. Most girls from lower social backgrounds, and many bourgeois ones, simply did not go out at night: they were prevented by their parents, and had to resort to subterfuge in order to frequent discotheques.

These processes of exclusion judged potential patrons on the basis of their symbolic capitals (in particular, the economic and the social ones) and also on their habitus. Bourdieu identifies the habitus in a series of pre-conscious dispositions that orient action (Distinction). The habitus is not only a matrix of one's attitudes produced by her social position, but it also has a bodily component - the hexis, which inscribes one's social history in the very body (see Bourdieu, Outline). Clubbing was thus a form of leisure that classified people along many different forms of the habitus: appearance, personal attitudes, body language - and, for women, a practice of subterfuge and escape from parental control.

\section{Working with the Enemy}

The emergence of an autochthonous electro scene reacted to the context presented above. And yet the upsurge of the scene modified the local geography of dance and nightlife in only a partial way. In 2014-2015, a clubber or a DJ who was interested in house music, techno, or dubstep, still had to frequent places which shared some features with the pre-revolutionary coastal clubs. For a DJ, being hired in such venues was actually a must do, if she wanted to make some money through music. A set by Hedi, a local house music DJ, shows how the 2014 dance scene still presented some traces of exclusiveness and was in part directed to a hedonism-seeking audience.

During that year, Hedi obtained the role of resident DJ in a lounge bar called Shooter Island. The Shooter Island was hosted by a tourist complex called Le Cap, in 
Gammarth (northern banlieue of Tunis). The entrance of the complex was strictly policed. My backpack was searched and I had to pass through a metal detector. The bar was glamorous. It had a minimalist design, two counters sponsored by a popular brand of vodka, and a wide terrace. Prices for drinking and eating were high, especially if compared to Tunisia's low cost of living. The bar catered dance music DJs, and yet it did not have a proper dance floor. The patrons, all in chic clothes, had to dance among the tables. Most of them, anyway, did not dance, although they seemed to appreciate the house selection mixed by Hedi. Like many venues in Tunis, the Shooter Island was not designed for dancing, and yet music was too loud to talk. I was dancing with some friends, when Rahim, another house music DJ, pointed something out to me. One of the patrons had ordered a bottle, which was served with a big bengala on its top. Rahim was disgusted: "You see, that's what Tunisians want. He ordered a bottle, and wants everybody to notice!" And while the Shooter Island was a rather "chic" venue, similar situations could be observed even at more blatantly underground sets.

Hedi was just one of the Tunisian musicians who unwillingly participated in the club scene. He had a clear understanding of the "structural" reasons that distanced Tunisia from his ideal of an electronic music scene, and he often disagreed with the choices of club managers, bouncers, state authorities, and audiences. Many of my informants were in a similar condition. They harshly conflicted with venue managers and owners about their pay and the way they were treated, and they often felt that the audience disrespected their art.

Once in 2014, I assisted with a DJ set by Boom Bass Tech, a predominantly female bass music collective. Boom Bass Tech used to organize a set every week in the same lounge bar; the collective members invited a new guest from the local scene every week. They had agreed with the lounge manager to be paid 150 Tunisian Dinars (or 
about \$65 US dollars in Feb. 2017) and five beers for each DJ, plus a 50\% cut on the price of further beers. At the fourth week, the manager told the DJs he had no pay for them, and they could only get five beers each. The collective fought the manager for weeks, but they never succeeded in obtaining their cachet. Eventually, they put the Boom Bass Tech project on hold. Fethi was a producer who made a name in the global "nu disco" scene and used to play in Europe more often than in Tunisia:

When I play abroad, my standard cachet is 1000 euros. Here I receive offers every day. And how much do they want to pay? 100, 200 dinars, and they tell me I can have five or six beers and a pizza. And I don't play. I only play when friends play; here I stress a lot. Some people know my music, but the rest go to places not to listen to the DJ: they don't even know who's the DJ. They sit, drink. ... Tunisia is crazy! I don't even know if there are any true music fans here. I'm sorry, but when I play in Tunisia I feel like I'm playing for cats or goats ... for animals. (Fethi). Fethi's disappointment with the Tunisian audiences was, as we have seen, quite shared. Those who managed the infrastructures of the scene were for the most part maniacs of electronic music and its history; they were hurt by the fact that many listeners did not share their passion and went clubbing for fun rather than strict commitment to the scene and the music. The electro scene could be interpreted as a cultural field driven by its party component. It had part of its raison d'etre in a promise of night-time (and festival time) sensual pleasure. Producers, DJs, VJs and the other scene members were part of a system that, they felt, employed them in often non-convenient and humiliating ways, and did not appreciate their deeper concerns and their artistic value.

The last Boom Bass Tech night, which I mentioned above, also showed something about the politics of nightlife in Tunisia. At a certain moment, towards the 
end of the night, the set of the guest DJ was suddenly interrupted. For a while, nobody including the DJ - knew what was happening. Music then restarted for a short while, before the end of the night. As one of the collective members explained to me, police had visited the bar twice. They sequestered a piece of the setup, so that the bar had to pay in order to have it back before the DJ could continue (Zahra). Such examples of everyday corruption and vexation were not at all rare in the nightlife industry or in any other segment of Tunisian society. Electro scene members sometimes represented themselves as examples of a government's campaign against art and culture. They saw the state's antipathy towards culture as an element of continuity with the Ben Ali regime, based on a will of governors to keep youthful and popular protest at the margins.

And yet such examples could not be read as symptoms of an exclusively topdown repression of art. For example, a well-known electro club had to shut down, in 2014 , because of the lobbying activity of a rival venue, which got the club closed and even, allegedly, commissioned the plunder of the club space. My informants related many episodes in which a venue called the police against competitors. As it had happened during the Ben Ali era, the governance of Tunisian society was established through the actions, and a subtle form of consent, of the dominated. Different parts of society conflicted, and used elements of the state to prevail on their enemies: the state thus penetrated society and controlled it through patronage and blackmail (see Hibou, Meddeb).

This dynamic was visible in the club circuit as well, and constituted an aspect of a broader conflictual character of the scene itself. Self-reputed underground scenesters fought against what they perceived as the mainstream; DJs fought against venue managers; musicians felt in conflict with their audience; different music collectives held 
conflicting ideas. Such a conflictual character can be read in terms of Keith KahnHarris's understanding of music scenes formed by construction and structure. The electro scene had to rest on the structure - that is, the set of infrastructures and the broader social dimensions - of the pre-existent club and nightlife circuit. While the underground was conceived as a reaction to the mainstream, it had to borrow its infrastructures. This equated to borrowing a scheme of conflicts, such as the ones stemming from the political governance of nightlife and from the social exclusiveness inherent to the Sahel social context. The difficulty of electro scenesters to adjust to the structure brought, in turn, to their permanent dissatisfaction with the club scene in which they existed. This prism of conflictual situations had consequences on the very construction of the electro scene. Pieces of the scene reacted in different ways to the mainstream, accepting and refusing different elements of it in order to adjust (and be adjusted) to the scene's structure. The different ways of adapting to the structure combined with the different social trajectories and aesthetic ideologies of electro collectives. For this reason, conflict and division marked the construction of the scene. In the next section, I will map the main fault lines of this conflict and explain its effects on the scene's existence and reproduction.

\section{Underground versus Underground: Turning Points: the Plug and Les Dunes}

\section{Electroniques}

The Tunisian revolution of 2010-2011 created the conditions for the local electro scene to expand and flourish. Moreover, the new visibility and success of the scene caused its further interconnection with the club circuit and the broader event, spectacle, and nightlife industry of Tunisia. Two events marked this new moment of expansion: the rise of the Plug, and the Dunes Electroniques. 
The Plug has been celebrated as the mythical place of the electro scene by nearly all of its members. Situated on the upper floor of a historical palace on the seaside of La Marsa (northern banlieue of Tunis), it was founded in 2011 by metalhead entrepreneur Khaled Trabelsi and by Ogra, the leader of an electro collective called Waveform. From late 2011 to early 2014, the Plug was the central meeting point for both Tunisian metalheads and electronic music fans. During the week it hosted rock DJ sets and metal concerts; on weekends, Waveform took control. The collective invited foreign techno artists - for example, producers like Octave and Shackleton - and gave room to most local DJs and producers to parade their music. In 2014, the venue had to close, citing "administrative reasons" as the cause for its shutdown, and its managers created a series of new venues called "The Plug” (such as Plug's Pub, or the Plug Hammamet),

Pre-revolutionary electro was constituted by an array of scattered and yet communicative experiences; the Plug brought such a landscape to a new synthesis. The venue's social organization rested on a blend of exclusiveness and inclusiveness: on the one hand, the Plug was the first nighttime place being vocally devoted to "alternative" people: bohemian youth, leftists, homosexuals, members of local spectacular youth cultures. In this respect, the Plug was an antithesis to the seaside mainstream panorama. On the other hand, Waveform managed to be as inclusive as possible in inviting musicians and collectives to perform. House, techno, bass music, experimental electronica were all listened and danced to in the venue. Entry fees and door selection were minimal (the latter was absent at the beginning), and drugs widely circulated. Some of my informants reported the Plug's atmosphere so welcoming that they did not mind its low cachets, or even played for free, since they felt like playing among friends. These features of the Plug were often linked to the revolution. Many of my informants considered the Plug as a space made possible by the revolution, as its atmosphere would 
have just been impossible under the Ben Ali regime. Ogra himself considered the Plug as a fruit of the political uprising. In 2011 he was disappointed by the scarce role of electro musicians in supporting the revolution, and he started to organize events to raise money in support of the blessed of the uprising. It was in this situation that he found and started to use the space that later became known as the Plug.

The other crucial event was a festival called Les Dunes Electroniques (The Electronic Dunes—see video, Les Dunes). The festival was organized in 2014 and 2015 by a French Agency and a Franco-Tunisian touristic entrepreneur in the Saharan Oasis of Nefta, and held on the set built for representing the Planet Tattooine in the 1977 movie Star Wars. The festival took place in February and presented international dance artists such as the German/Mexican duo Pachanga Boys and the French duo Acid Arab, a project mixing techno and house with "oriental" samples. DJs from the Tunisian collectives Waveform and FRD were also scheduled.

The event was packaged with the aesthetics of Saharan tourism and the exoticism of folkloric Tunisia. Its advertisement made use of images of dunes and oases, and references to the Berber culture of the Sahara. Star Wars was a central element of the Dunes' imaginary as well with characters from the movie used to promote the festival. And while the Dunes Electroniques used the diverse touristic and heritage appeal of Southern Tunisia to sell itself, the Tunisian government used the festival in order to sell Tunisia. Amel Karboul, then Minister of Tourism, personally inaugurated the event, sponsoring it as a sign of the accomplished democratization of the country after years of painful - and at times fragile - political transition. One of the Dunes' slogans was, indeed, "It's time to celebrate!" It indicated the end of the immediate post-Ben Ali period, which was marked by political violence and terrorism, and promised a new beginning for a joyful, secular, and cosmopolitan youth wanting to 
have fun and enjoy democracy. "Fun" was a keyword for the new tourist strategy of the country, aimed at qualifying the image of Tunisia (Kribi; Bel Aïba). In this sense, the Dunes were part of a narrative that attempted to reconstruct a tourist genealogy for the post-revolution electro scene.

Reviews of local electro scenesters on the Dunes Electroniques was mixed. Many of my informants praised it as a cool party occasion, but could not praise the consistency of the music, which was not always high. However, few understated the cultural importance of the event. The Dunes Electroniques succeeded in popularizing electro in Tunisia as a legitimate cultural form and a potential success for tourism and international visibility (as the Dunes attracted patrons from abroad).

The 2015 edition was not as successful as the previous year's, due to heavy rains that caused the cancellation of much of the festival. However, the Dunes Electroniques made a central contribution in normalizing the festival landscape of Tunisian electro after the immediate post-revolutionary period, when such festivals were hardly conceivable because of security issues and political instability. By 2014 and 2015 festivals multiplied, with events such as the summertime Ephemere festival (staged in Hammamet) raising the bar in terms of successful organization and musical ambitions.

\section{Collectives and Positions within the Electro Field}

The Plug experience, and the new festival panorama inaugurated by the Dunes, contributed in shaping the new, post-revolutionary electro scene. Local self-alleged underground activists were disseminated all through the club circuit and its media; Tunisian DJs signing for foreign labels gained a new visibility in their homeland; the overall musical offerings became more diverse and clubbers became more acquainted with them. While my informants diverged on this point, some of them stated that 
Tunisians were developing "the ear" for electronic music, thanks to the new underground supply and to the existence of new specific scene infrastructures: festivals like the Dunes, Ephemere, Tomorrow Island, Pop in Djerba, or the smaller Joussour and Robinsonore; web journals such as Zoopolis and People's Beats; web radios like Medelina Beats and Radyoon. And while, as we have seen above, electro scenesters had to negotiate the structure of their scene with a club setting that did not completely respond to their idea of the underground, they did it in different ways, thus producing an equally diverse and asymmetric scene.

Collectives can be seen as a point of access for understanding the organization of Tunisian electro. They were groups of DJs, producers, and other artists that shared a common artistic identity that did not fully encompass the activity of their members. That is, members of collectives did not always play together, and they sometimes took part in more than one collective at once. As an example, DJ Zinga from Waveform participated in the UNITY (reggae/dub/bass music) soundsystem with Shenz, one of the representatives of World Full of Bass. Producer Deena Abdelwahed, whose compositions managed to find a way to fuse Tunisian folk and popular music with ghettotech sounds, was both a member of the above-mentioned Boom Bass Tech project and of the French-based "oriental electro" collective Arabstazy. In this sense, collectives were present even before the revolution, and are a feature of electronic music scenes worldwide. Their actual shape could be a cultural association, a soundsystem, a "concept" (that is, the brand of a regularly scheduled club night), a label. One collective could embody more of these shapes altogether: for example, Waveform was, at once, an association, a label, and the concept that organized the first events at the Plug. As a collective, Waveform had the double aim of pushing alternative culture forward and pluralizing it. This aim was reflected in the Plug's activity. During the weekends, 
Waveform invited DJs from all sides of the scene and music genres to their events, like "Shut Up and Dance!" and "Alert! Alert!" As one of their members, Omar, told me, The idea was to mix all styles, from the edgier techno stuff to Italo-disco: “done with scene division, done with elitism, we're sick!" In the beginning it was "Shut Up and Dance!" every Thursday, then, step by step, we started opening all week long and inviting everybody to play with us. And things started moving. Tunisians wanted something new. The Plug started to attract every kind of people: the curious ones, those who did not go out because they didn't know there was such a scene, those who listened to this music only abroad, all social classes. Today the scene is alive and well. The quality is high, people enjoy edgier DJ sets. I'd say that Waveform mission, an education of the ear - or, rather, a gymnastics of the ear - succeeded. Of course, there have also been arguments. Somebody did not want to drop his elitism, and some of them detest me because I vulgarized the music. (Omar)

Omar's polemic about elitism struck a crucial nerve in the scene. The pre-revolutionary pioneers of Tunisian electro had refused the regime-sponsored hedonism of the club circuit, which hegemonized the nightlife in the country. Most of them were intellectuals from the higher middle class. They invested their music with a culturally and politically defiant meaning, refusing at once the economic elitism and the musical populism of the perceived mainstream. Controversy on elitism created tension between the members of World Full of Bass, as one of the collective's former members told me. Accusations of intellectualism and elitism also hit the E-Fest, whose program was considered by some as too highbrow. In 2010 I went to a side event of the festival, set at the Acropolium, a desecrated Byzantine cathedral surmounting Carthage. It was a dub/dubstep set, 
scheduling two members of World Full of Bass, among others. Alcohol was not sold in the venue, and most of the audience crowded the parking lot. They listened to Shakira in their cars and drank beers, only seldom taking a walk inside the Acropolium. Aziz, one of the E-Fest organizers, thus commented on the supposed elitism:

During the time of dictators we were a targeted culture. It was the State that decided what would be diffused and what would not. All that was forbidden was diffused clandestinely, and everything that targeted mass audiences was formatted. This kept people in a form of ignorance of the cultural object, and of the ways to consume it. People don't know how to consume it. ... They are starting to learn how to consume a festival. In most cases, they consume a festival as they would consume a club night. It is the degree of interpretation that is in question here, and such a degree increases only if the public is used to consuming. Today, for us, this is the problem in Tunisia. That for decades we've been having a degree of reading of works of art that was limited because it wasn't diversified enough, and today new works are proposed, which go out of such compartmentalization and push people to have a different scope. But we're still at the beginning. People in Tunisia are learning to consume, whatever they're consuming. (Aziz)

Experimental musicians kept on criticizing the facets of the scene most perceived as "mainstream" or populist - an avant-garde producer told me that the Plug was a place for music that "has no meaning, music for the drunks" (Haythem). On the opposite side of the spectrum, some ambits of the scene refused cultural elitism pushing on the party side of the electro imaginary. The work of FRD Krew was the most important example of this tendency. The monicker FRD meant both "Friday" and "Friends." This double 
meaning functioned as a cultural statement; on its Facebook page, FRD presented itself as "a collective of multidisciplinary artists who gathered around a common will to contribute to the development of a veritable alternative and urban culture in Tunis" (FRD).

FRD's vocation aimed both at partying and at pushing alternative culture forward; their coolness was rooted both in urban aesthetics coming from funk and hip hop and in digital culture and fine arts. FRD managed the music schedule of the Carpe Diem, perhaps the most important post-Plug hub of the scene and one of the few discos with an actual dance floor in the Tunis area. FRD sets catered urban grooves and electronic funk to the audience of the Carpe Diem, which was constituted by the encounter of local "alternative youth" and party-going middle classes. The Carpe Diem's slogan was Only for Good People. It signified the club's atmosphere, at the same time glamorous and easygoing. And yet the slogan well exemplified the critiques attracted by both the venue and its managing collective. Some actors of the scene despised the Carpe Diem for being an exclusive place, aimed at rich kids.

While scenesters designed the borders of the underground in different ways, many of them converged in considering house music as beyond the border, as the most commercial facet of the scene. But house, with other classic dance floor musics such as old school techno and nu disco, presented one of the most feverish ambits of reflection on the underground and refuse of the mainstream. This section of the scene was composed by musicians such as Hamdi Ryder, HearThug, Enfants Malins, Haze-M, and Dawan (an IDM musician, but very passionate about the history of original techno and house music), and collectives such as Downtown Vibes and Dance Till Death records. Some of these artists (for example Haze-M and HearThug) gained visibility worldwide, and were able to play abroad and compare foreign scenes with the Tunisian one. They 
coupled danceable and accessible music with sophisticated reflections about the underground. Many of them had a unique take on authenticity, paraded a will to educate their audiences about the "real" underground, and were disgusted by the "fake" underground posers that, in their opinion, crowded the Tunisian scene.

Underground, for techno and house scenesters, was a matter of symbolic practices. They prized knowledge of subgenres and musical history, disapproving listeners and DJs that could not tell the difference between tech-house and deep techhouse - producer Aksel told me that his definition of underground could be synthesized in a quotation from American producer/DJ Moodymann: "Educate yourself” (Aksel). They often told me about their music careers as manic and sleepless as they were totally discipline in their musical study, use of software, and composing/practicing routines. They described to me days and nights spent in front of their laptops, which prevented them from getting a "normal" job. This routine condemned some of my informants to a precarious life, and pushed them to compromise with venues and opportunities for playing which contradicted their musical principles. As a result, DJs suffered from comparing their dedication to the pleasure-seeking attitude of clubbers. As Saber, a music journalist, explained to me, “We don't sleep at night! We don't expect others to do like us, but it would be nice if people got interested [in music] in a different way than simply partying. It's a whole culture that would be thus nourished" (Saber).

The emphasis on discipline and symbolic practices of techno and house musicians, and their belief in the educational importance of the underground, brought them to polemize with various aspects of the local scene - for example the nearly complete nonexistence, in Tunisia, of a vinyl market and the scarcity of DJs using physical records instead of software such as Traktor. This controversy on software versus records has been discussed in the case of "western" electro scenes (see Montano; 
$\mathrm{Yu}$ ), and has been understood in terms of a practice of distinction and qualification of DJs. Some Tunisian DJs refused to play abroad, or play tout court, because of their inability to spin vinyl records or CDs. In their case, however, the pure need for distinction and self-assertion coexisted with local concerns, based on policing the border between the "true" underground and the "fake" mainstream. When I asked Hedi, a popular house DJ, why he preferred vinyl over Traktor and MP3 files, he explained, It's not a matter of quality or taste, the problem is something else. DJs play, since the seventies. A DJ is not a jukebox: he mixes, he chooses vinyl records, he does his job. If you start taking all those things away, anybody can be a DJ, and the ending is catastrophic. Like, for example (laughing), all the PRs that become DJs! $!^{5}$ Tunisia is full of that, because if you wanna play around here you have to bring people [to the club], and PRs have already got lots of contacts. Also, those who are considered as the best DJs in Tunisia are actually a bunch of rich guys full of "friends," whom they bring to the parties where they play shitty music. I can understand that clubs have their exigencies, but you can also throw good parties while educating the audience. (Hedi)

For Hedi, the devaluation of DJs only reinforced the mainstream club circuit, a system in which music was disregarded in favor of party dynamics - for which simple PRs took the role of DJs.

Downtown Vibes, a collective from Tunis, embodied similar concerns in the events it organized: Secret Vibes and Friday Is a Wax Day. Secret Vibes was a series of private parties held in "secret" locations - often in downtown Tunis, which was seemingly unique in the dance panorama. Downtown Vibes DJs played alongside invited artists; spectators were asked to pay a sum and share some alcohol. 
Superficially, Secret Vibes could seem an occasion for scene elitism, a concept that kept "non-initiated" listeners unaware. Actually, members of the collective interpreted it as a way of dancing without having to deal with the costs and rules of the elitist club world. Alcohol prices and entry tickets were controlled, the ambiance was easygoing and friendly with no need for dress codes and the like (see Aftermovie). Friday Is a Wax Day was an event, often organized in Tunis cafes, during which people could share their vinyl records and listen to them. Again, it could be seen as a highly exclusive event, aimed at vinyl junkies in a country in which vinyl was more than rare. Yet the atmosphere at these events was fairly more inclusive. Tunisian youth had a chance to play discs they had found at home, and they could talk and discover new music. Friday Is a Wax Day thus created a context for musical contact and sharing that was rare outside of socially and economically sanctioned situations.

\section{Scene Dynamics}

As I presented them above, Tunisian collectives embodied different ways of conceiving electro and the underground; therefore, they conceived the mainstream in different ways and engaged with it through divergent modalities. In a small scene, like the Tunisian one, everybody knew each other, and collectives frequently communicated and collaborated. When a collective had a residency in a club, it often hosted external DJs coming from other collectives or playing as independents. This was the most common way for collectives to interact - an interaction that constructed the scene as a common social ambit. Of course, divergences and controversies (and sometimes arguments) between collectives equally shaped the scene construction in the sense of Kahn-Harris. This game of communication and conflict, and the different logics that drove scene interactions, can be seen through Pierre Bourdieu's notion of field, which I described in 
the introduction. In a similar vein, the different facets of the scene interacted in a game of opposed positionings, moved by logics and concerns that certified the influence of external social forces on the scene and, in turn, reproducing those forces in a refracted way. In the case of Tunisian electro, the refuse of intellectual or socioeconomic elitism testified to a reaction of the driving forces of cultural and economic capital. At the same time, those forms of capital informed the different ways of actors in engaging with the field - their habitus. Keith Kahn-Harris has individuated scene-specific forms of the habitus in mundanity and transgression, as principles that stemmed from forms of symbolic capital proper to the scene he studied - he thus employed the concept of "subcultural capital," which has been used by Sarah Thornton, for example, to explain symbolic distinction within British club culture.

In Kahn-Harris's sense, mundanity is a sober and disciplined approach to the apparently spectacular world of youth culture. It is made of hard work, the struggle for connoisseurship, everyday commitment. The seriousness of mundane subcultural capital is counterpoised to transgression, intended as an emphasis on spectacular conducts and the breaking of boundaries. In a sense, we can see the "true underground" preoccupation of many Tunisian scenesters (in particular, the house and techno ones described above) as a way to restore mundanity in a scene characterized by hedonism and bodily transgression.

But, unlike typical Bourdieusian analyses ${ }^{6}$, one cannot easily make a parallel between the positions in the Tunisian electro field and the social dispositions (as produced by different class backgrounds) of actors. The scene was too small to show a consistent parallel between one's social background and her display of mundanity and transgression - and, in turn, her refusal of intellectual or social elitism. Most members of the electro scene came from different fractions of the local middle classes. They had 
difference in incomes and actual life possibilities, with many of the most "intellectual" scenesters being indeed quite privileged, educated, and cosmopolitan (in a country that denied the freedom to travel to most of its citizens). But none of the main positions on the field was strongly representative of lower classes as, for example, the local rap scene was (Barone). As a consequence, both the refusal of intellectual and social exclusiveness ended up closing the space of electro to most low-income Tunisian youth. Some of my informants rejected such a form of exclusion, stating that they would prefer poor yet interested patrons to rich yet non-music loving ones. But, as a matter of fact, the lack of economic resources was not the only thing that kept the poor out of the electro circuit. Knowledge of the music was not equally available nor appealing for every social niche, and the mastering of the codes of dancing in promiscuous spaces in which alcohol and drugs circulated was often unavailable to disadvantaged Tunisians, especially to those who did not come from the Sahel and from metropolitan spaces.

This was particularly visible at events such as Festivals and rave parties. At both editions of the Dunes Electroniques, for example, some patrons complained about the behavior of young men from the nearby towns, accused of having fun in a loud and disrespectful way, of singing stadium sing-alongs above the music, harassing women, and stealing from other dancers. Similarly, the organizers of some private parties and raves in the rural areas of Tunisia told me of accidents started after local boys had obtained access to the dance floor. According to my informants, those youth did not know how to behave at such events; they got heavily drunk, and even started fights (Nessim; Philippe). The way of interacting "appropriately" on a dance floor was indeed tied to one's social background and acquaintance with the transnational world of electronic dance music. The often deprived social reality of Tunisian youth made occasions like Festivals or electronic music events something they would not renounce, 
and which they welcomed with extreme and transgressive joy. This transgression reinforced scenesters' perceptions of those youth's “wrong” hexis. While many actors of the scene politically refused elitism, it was in part inscribed in the unspoken practical norms of the scene. ${ }^{7}$

\section{Conclusion}

The Tunisian electro scene developed in contrast to a mainstream nightlife scene. This mainstream was individuated in the clubs of coastal Tunisia, which embodied the heritage of the elitist tourism politics of the Ben Ali regime as well as the desire for hedonism of Tunisian privileged youth. But beside these features, the various actors of the electro scene conceived the mainstream in divergent ways, and thus thought of the electro underground in divergent ways. They built the underground out of defiance to the mainstream, but had to negotiate with pieces of it in order to have spaces for playing, audiences, and jobs.

In the terms of Keith Kahn-Harris, the structure of the electro scene - its materials, infrastructural texture - was partly borrowed from the mainstream, and bore its political and social underpinnings. Different actors of the underground - for instance, the different collectives animating it - took or refused different pieces of the mainstream, thus producing different conformations of the underground and of its compromise with the mainstream. The main lines and driving forces of this practice of selection were their attitudes towards the intellectual and the social elitism present in the scene. Those who totally refused the mainstream produced a markedly intellectual scene, while others contested the need for the scene to be culturally inclusive, even if this practically meant to "accept" the norms of class-based selection of the main club circuit. The only experience in which cultural variety and social inclusiveness seemed to 
coexist was the Plug, but after its closure further attempts failed. As a result, the scene was made of communicating sections that held contrasting positions about what "underground" meant. For this reason, compromise with the scene's structure resulted in a conflicting construction - in Kahn Harris's terms, the underlining discourse, and common identity narrative of the scene. And yet the different positions were unable to totally eliminate elitism from the scene and to become representative of lower classes, who in most cases could not access the venues and other spaces of the scene.

Many of my informants remarked on the divisiveness of the Tunisian electro scene. Some of them despised the scene for being "clan-based." Collectives allegedly had the fault of creating their own niches and were not willing to cooperate. ("Independent" artists held the strongest grudges about this situation). Yet this divisiveness went hand in hand with an actual growth of the scene, of its fortunes and its fame. New festivals continually arose; new DJs appeared every month with some attaining a reputation in global electro. How could this apparent paradox be explained? Perhaps, the multiform shape of the underground-mainstream link structured the scene in a socially attractive fashion. The scene did not lose its classic party-going audiences, which were not necessarily interested in learning more about the music or becoming scene activists. At the same time, it acquired a new public of committed, expert scenesters who closely followed local and foreign artists. Conflict in the scene produced a fruitful ambiguity, in which the blurred line between underground and mainstream worked as an inclusive device, which gathered different sections of the local, secular middle classes around common social spaces of culture and entertainment. At the same time, both the Islamic middle class and the vast disadvantaged youth of the country could not access the scene. In this sense, the growth of Tunisian electro highlighted the social and cultural contradictions of the new, post-revolutionary democratic state. 


\section{Notes}

1. Names have been changed to protect the privacy of informants.

2. In a similar way, Geoff Stahl describes scenes through the interaction of their hard and soft infrastructures. Hard infrastructures are the physical institutions of a scene, while soft infrastructure is the discourse that gives the scene cohesion.

3. On the relationship between the regime and tourism, see Hazbun; Di Peri. On the broader link between repression and economic corruption, see Hibou.

4. See Shinigami San [Live_WFOB_2012] for a video of a Shinigami San's performance at the celebration of WFOB's third birthday.

5. By PRs, Hedi means "Public Relations": people who promote a club night and bring customers to a venue through inserting them in their "lists."

6. See for example Bourdieu's work on the field of cultural production in nineteenthcentury France (Rules). For similar analyses in popular music scholarship, see O’Connor.

7. Arun Saldanha makes a similar point about trance events in Goa, India. But in his case, exclusion is based on racial terms. 


\section{Works cited}

Aftermovie Video for Secret Vibes \#9. Uploaded by Downtown Vibes. YouTube. 8 Sept. 2016. <https://www.youtube.com/watch?v=eGWJCux_Bns>.

Aksel. Personal interview. 12 March 2015.

Amin. Personal interview. 27 May 2015.

Aziz. Personal interview. Translated from French. 7 July 2014.

Barone, Stefano. "Feeling so Hood: Rap, Lifestyles, and the Neighbourhood Imaginary in Tunisia.” British Journal of Middle Eastern Studies (2017): 1-16. Web.

Bel Aïba, Ines. "Pour Récupérer ses Touristes, la Tunisie Veut Changer son Image." El Huffington Post Maghreb, 21 March 2014. Web. 14 Feb. 2017 <http://www.huffpostmaghreb.com/2014/03/21/image-tunisie tourisme_n 5005724.html>.

Bennett, Andy. "Subcultures or Neo-tribes? Rethinking the Relationship between Youth, Style and Musical Taste.” Sociology 33 (1999) 599-617. Print.

Bennett, Andy, and Keith Kahn-Harris, eds. After Subculture. Critical Studies in Contemporary Youth Culture. Basingstoke: Palgrave/Macmillan, 2004. Print.

Bennett, Andy, and Richard A. Peterson, eds. Music Scenes: Local, Translocal and Virtual. Nashville: Vanderbilt UP, 2004. Print.

Bourdieu, Pierre. Distinction: A Social Critique of the Judgement of Taste. Cambridge MA: Harvard UP, 1984. Print.

---. Outline of a Theory of Practice. Cambridge: Cambridge UP, 1977. Print.

---. The Rules of Art. Genesis and Structure of the Literary Field. Stanford: Stanford UP, 1996. Print.

Chouika, Larbi, and Eric Gobe. Histoire de la Tunisie depuis l'Indépendance. Paris: La Découverte, 2015. Print.

Dahmani, Frida. "Destination Clubbing.” Jeune Afrique. 23 July 2010. Web. 13 Feb. 2017. 〈http://www.jeuneafrique.com/195924/societe/destination-clubbing>. 
Di Peri, Rosita. “An Enduring 'Touristic Miracle' in Tunisia? Coping with Old Challenges after the Revolution." British Journal of Middle Eastern Studies, 42 (2015) 104-18. Print.

Les Dunes Electroniques-Aftermovie 2014. Official video. YouTube. Uploaded by Amine Skhiri. 6 March 2014. https://www.youtube.com/watch?v=r5mjftLSKSw

Emna. Personal interview. Translated from French. 4 July 2014.

Farrer, James. "Disco 'Super-Culture': Consuming Foreign Sex in the Chinese Disco Cosmopolitan Dance Culture and Cosmopolitan Sexual Culture.” Sexualities 2 (1999) 147-65. Print.

Fethi. Personal interview. 22 May 2014.

FRD \& Friends Facebook Page. Web. 14 Feb. 2017. <https://www.facebook.com/pg/frdandfriends/about/?ref=page_internal $>$

Haythem. Personal interview. Translated from French. 24 March 2014.

Hazbun, Waleed. "Images of Openness, Spaces of Control. The Politics of Tourism Development in Tunisia." The Arab Studies Journal 15/16 ; 2/1 (Fall 2007, Spring 2008): 10-35. Print.

Hedi. Personal interview. Translated from French. 28 May 2014.

Hibou, Béatrice. La Force de l'Obéissance. Économie Politique de la Répression en Tunisie. Paris: La Découverte, 2006. Print.

Kahn-Harris, Keith. Extreme Metal: Music and Culture on the Edge. London: Berg, 2006. Print.

Kribi, Adjil. "Les Dunes Électroniques: 'Rencontre du Troisième Type sur une Galaxie très très Lointaine'.” El Huffington Post Maghreb. 25 Feb. 2014. Web. 13 Feb. 2017. <http://www.huffpostmaghreb.com/2014/02/25/duneselectroniques_n_4851967.html>

Malbon, Ben. Clubbing: Dancing, Ecstasy, Vitality. London: Routledge, 1999. Print.

Meddeb, Hamza. “L'Ambivalence de la «Course à “el Khobza'”». Obéir et se Révolter en Tunisie." Politique Africaine. 121 (2011) 35-51. Print. 
Melechi, Antonio. "The Ecstasy of Disappearance." Rave Off: Politics and Deviance in Contemporary Youth Culture. Ed. Steve Redhead. Avebury: Aldershot, 1993. 29-40.

Montano, Ed. “'How do you know he's not playing Pac-Man while he's supposed to be DJing?': Technology, Formats and the Digital Future of DJ Culture.” Popular Music 29.3 (2010). 397-416. Print.

Nessim. Personal interview. 28 March 2014.

O'Connor, Alan. Punk Record Labels and the Struggle for Autonomy: The Emergence of DIY. Lanham: Lexington, 2008. Print.

Omar. Personal interview. Translated from French. 8 May 2014.

Philippe. Personal interview. 18 Feb. 2015.

Redhead, Steve, ed. Rave Off: Politics and Deviance in Contemporary Youth Culture Aldershot: Avebury, 1993. Print.

Rietveld, Hillegonda. "Living the Dream." Rave Off: Politics and Deviance in Contemporary Youth Culture. Ed. Steve Redhead. Avebury: Aldershot, 1993. 41-89.

Robinson, Caitlin. "Wasta Capital: Ethnographic Reflexivity at a Rooftop Nightclub in Beirut.” Dancecult: Journal of Electronic Dance Music Culture 5.1 (2013). Web. 9 Feb. 2018. <https://d.dancecult.net/index.php/dancecult/article/view/359/364>.

Saber. Skype interview. Translated from French. 29 March 2015.

Saldanha, Arun. Psychedelic White: Goa Trance and the Viscosity of Race. Minneapolis: U of Minnesota P, 2007. Print.

Shinigami San [Live_WFOB_2012]. Uploaded by Aly Bouzwida. YouTube. 27 Dec. 2012. https://www.youtube.com/watch?v=q2Q1tOAsXls.

Stahl, Geoff. “'It's Like Canada Reduced': Setting the Scene in Montreal.” After Subculture: Critical Studies in Contemporary Youth Culture. Ed. Andy Bennett and Keith Kahn-Harris. Basingstoke: Palgrave, 2004. 51-64 Print.

St. John, Graham. Technomad: Global Raving Countercultures. London: Equinox, 2009. Print. 
Thornton, Sarah. Club Cultures: Music, Media, and Subcultural Capital. Hanover: Wesleyan UP, 1996. Print.

Yu, Jonathan. "Electronic Dance Music and Technological Change: Lessons from Actor-Network Theory" DJ Culture in the Mix: Power, Technology, and Social Change in Electronic Dance Music. Ed. Bernardo Attias, Anna Gavanas, and Hillegonda Rietveld. 151-72. Print.

Zahra. Personal interview. 29 May 2014. 